
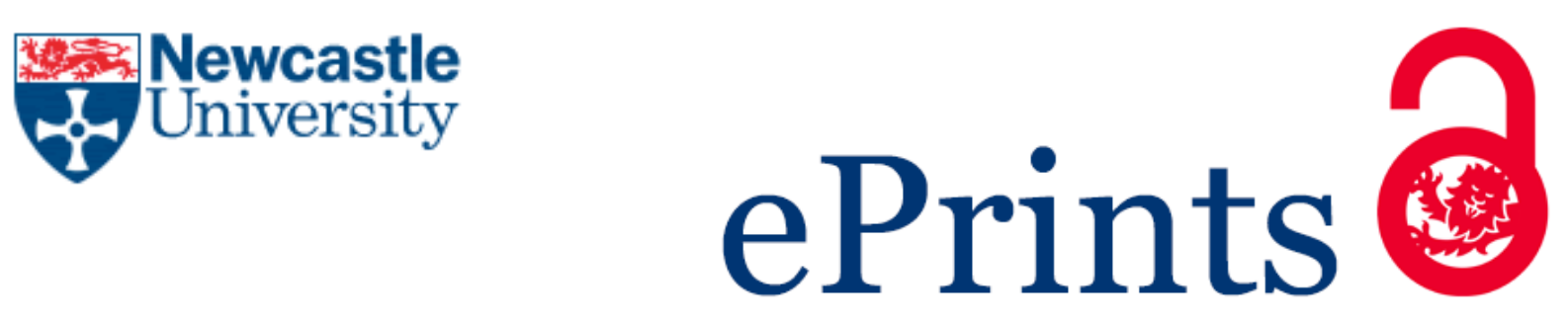

Huo F, Li B, Chong A, Yannopoulou N, Liu MJ.

Understanding and predicting what influence online product sales? A neural

network approach.

Production Planning \& Control 2017, 28(11-12), 964-975.

\title{
Copyright:
}

This is an Accepted Manuscript of an article published by Taylor \& Francis in Production Planning \& Control on 11/07/17, available online: https://doi.org/10.1080/09537287.2017.1336791

DOI link to article:

https://doi.org/10.1080/09537287.2017.1336791

Date deposited:

$13 / 10 / 2017$

Embargo release date:

11 July 2018

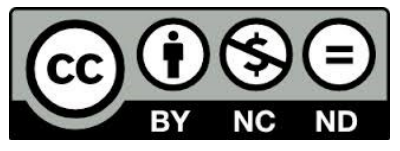

This work is licensed under a

Creative Commons Attribution-NonCommercial-NoDerivatives 4.0 International licence 


\section{Understanding and predicting what influence online product sales? A neural network approach}

\section{Fangfang Hou}

Nottingham University Business School (China), University of Nottingham Ningbo China

Boying Li

Nottingham University Business School (China), University of Nottingham Ningbo China

Alain YL Chong

Nottingham University Business School (China), University of Nottingham Ningbo China

\section{Natalia Yannopoulou}

Newcastle University Business School, Newcastle University, UK

Martin J. Liu*

Nottingham University Business School (China), University of Nottingham Ningbo China

*Corresponding author: Dr. Martin J. Liu. Address: The University of Nottingham Ningbo China. 199 Taikang East Road, Admin. Building, room 358, Ningbo, 315100, China.

Telephone: +86(0)574 88180000 Fax: +86(0)574 88180188.

Email: Martin.Liu@Nottingham.edu.cn

The authors are grateful for the financial supports from the National Natural Science Foundation of China (NSFC) (NSFC Project \#71402076) 


\title{
Understanding and predicting what influence online product sales? A neural network approach
}

\begin{abstract}
Understanding the factors that influence sales is important for online vendors to manage their supply chains. This study aims to examine the roles of online reviews and reviewer identity in predicting product sales. With Amazon data captured using our big data architecture, this study performed sentiment analysis to measure the sentiment strength and polarity of review content. The predicting powers of sentiment together with other variables are then examined using neural network analysis. The results indicate that all proposed variables are important predictors of online sales, and among them helpful votes of reviewer and picture of reviewer are the most influential ones. The findings of this study can be helpful for online vendors to manage their businesses, and the big data architecture and methodology can be generalized into other research contexts.
\end{abstract}

Keywords: big data; neural network; online reviews; product demands; online marketplace; reviewer identity

\section{Introduction}

Supply chain management (SCM) which aims to effectively integrate suppliers, manufacturers, distributors and customers is recognized as a significant element in organization's performance in an increasingly competitive business environment (Chong et al., 2016; Koh et al., 2007; Themistocleous et al., 2004). In response to the intensifying competition, the implementation of information technologies (IT) in SCM has become increasing important (Croom, 2005; Huang et al., 2015). It enables organizations to share real time information, reduce cost, increase customer satisfaction and improve productivity (Lee \& Whang, 2000; Rahman, 2004; Themistocleous et al., 
2004). However, organizations are still faced with one of the biggest traditional challenges - over purchase or under purchase when making purchasing orders, due to the variability of customer demand. Controlling uncertainty in customer demand is therefore considered as a key to the effectiveness of SCM (Lambert \& Cooper, 2009). With better understanding and prediction of customer demand, it reduces risks such as Bullwhip effect, increases the effectiveness and efficiency of SCM, and in turn contributes to the organization's competitiveness (Chong et al., 2015).

Data captured from online marketplace offers opportunity to better understand customer demand and make prediction of product sales (Duan et al., 2008). The trend of using IT and big data analytics to forecast product sales based on data from usergenerated contents (UGC) is emerging (Chong et al., 2015). UGC is seen as one of the most powerful channels to generate online word-of-mouth (Duan et al., 2008; Pan \& Zhang, 2011). It has a profound effect in online marketplace as online customers tend to refer to customer-generated reviews to make purchase decisions (Forman et al., 2008; Ghose et al., 2012; Liu \& Park, 2015). A large number of studies have paid attention to how online reviews can affect product sales and purchase intention (e.g., Duan et al., 2008; Park et al., 2007; Zhu \& Zhang, 2010). Given the importance of online reviews, more and more online communities encourage customers to post opinions and recommendations of products in order to attract new consumers and retain existing ones. Amazon.com and Alibaba's Taobao.com are two successful examples.

Relationship between the online review and product sales is based on the assumption that review provides valuable information of product to potential customers 
(Forman et al., 2008). Great research efforts then have been made to explore the impact of online reviews concentrating on the quantitative characteristics such as review rating valence and volume of review (Filieri, 2015; Pan \& Zhang, 2011, Zhu \& Zhang, 2010) while little work considers the effects of sentiments in online reviews, overlooking the variability and complexity of reviewer comments. Moreover, whether these review characteristics can lead to a better prediction of product sales requires further exploration.

More recently, reviewer profile information is provided to online customers as well as the review information. Researchers have argued that quantitative characteristics of online review are insufficient to explain customer perceptions, and reviewer characteristics should also be taken into consideration (Liu \& Park, 2015). They have shown that reviewer characteristics can influence people's confidence towards the information in the review (Baek et al., 2012; Fang et al., 2016; Liu \& Park, 2015; Racherla \& Friske, 2012). However, little is known yet about the role of reviewer characteristics in product sales. Forman et al. (2008) have argued that it is possible for online customers to rely on source cues only to make decisions. Therefore, exploring whether reviewer characteristics can lead to better understanding of product demand will be an interesting undertaking.

Given previous limitations and challenges, this study suggests a research approach combining not only the quantitative characteristics of online review, but also sentiments in online reviews and the characteristics of reviewer to better understand customer demand, which in turn contributes to SCM efficiency. Moreover, quantitative 
characteristics of online review, review sentiments and reviewer characteristics are not independent but rather exposed to online customers together. It indicates that these three aspects may interplay with each other and together shape online customer's behavior. Taking this into consideration, the interaction effects between review sentiments, review ratings valance and reviewer ranking have also been investigated in the study. With the purpose to better understand online customer's purchase decision, we have made use of real data captured from Amazon.com instead of data from web experiment (e.g., Lin et al., 2012; Sparks \& Browning, 2011). Big data is defined using the notion of Vs: volume, velocity and variety. Given these features, we have applied a big data algorithm which captures data that is in real time and covers all information available for the product and reviewer. More specifically, the algorithms in the study have used asynchronous Input/Output (I/O) to request, extract and preprocess data in real time from Amazon.com. Using SentiStrength and a Natural Language Processing Application Programming Interface (NLP-API), the sentiment of a review has been measured by both polarity and sentiment strengths based on the review texts. Furthermore, neural network analysis has been employed to examine whether the variables can be useful to make prediction of customer demand and product sales, and under what conditions it can be a more important predictor by investigating the interaction effects.

The study is designed to extend previous research in several important ways. It first contributes to the work on SCM by exploring how to make prediction of product sales using real data from online market place. Secondly, it contributes to the research 
concerning online customer behavior by evaluating whether quantitative characteristics of online reviews, sentiments in online reviews and the characteristics of reviewer can be helpful in predicting customer purchasing decision. Thirdly, we highlight how the interaction of review sentiments, review ratings valance and reviewer ranking can result in better prediction of product sales. Last but not least, in the process we make a methodological contribution in better understanding the online customer demand by combining big data technologies and architecture with neural networks and sentiment analysis.

\section{Literature review}

\subsection{Online reviews}

Consumers increasingly take upon a number of different roles in the online context. They enthusiastically volunteer in creating online content, posting it on the internet, distributing it and consuming it as well (Ashley \& Tuten, 2015). On one hand, the role of organisations and their operations are challenged as their control over their brands weakens (Simonson, 2015; Simonson \& Rosen, 2014). On the other hand, producers and consumers of online content merge into being prosumers (Kozinets et al., 2008) who then become significantly influential in consumers' perceptions and formed opinions towards product offerings. This in turn, affects product sales intentions.

Online reviews refer to internet users' shared opinions with each other on products and services (Tirunillai \& Tellis, 2012). They have also being examined in literature as User Generated ratings (Kozinets, 2016), User generated reviews (Tang et 
al., 2014), e-UGC (Lu et al., 2013) and eWOM (Clemons et al., 2006). Online reviews are perceived by consumers as more readily available (Bakos \& Dellarocas, 2011) and reliable than traditional promotional methods that tend to be viewed with scepticism (Godes \& Mayzlin 2004; Mudambi \& Schuff, 2010). This is due to the fact that both positive and negative information is included, often accompanied by explanatory features such as photos and videos, providing a more in depth and better balanced understanding of the offer in question (Floyd et al., 2014).

The studies examining online reviews can be seen as having expressed an interest in investigating the following key areas: The antecedents of such reviews and the motivations of people who engage in them (Kumar \& Benbasat, 2006), as well as, the benefits that they perceive receiving through such activity (Klaus, 2013); The type of online review based on its purpose such as to explain, justify or provide in depth knowledge; The assessment of the reviews' quality (De Langhe et al., 2016) and credibility, given the anonymity (Jensen et al., 2013) of the reviewer who cannot often be identified as being repeated or novice user of the product or even a third party i.e. masked user employed by a marketing firm (Jensen et al., 2013); The consequences of such reviews in areas such as users' experience (Kozinets, 2016), product types (Mudambi \& Schuff 2010), previous review ratings (Moe \& Trusov 2011), consumers' purchases (Basuroy et al. 2003; Chong et al., 2016; Liu 2006) and product prices (Li \& Hitt 2010).

Nevertheless, it is worth stating that previous research often offers conflicting explanations in similar phenomena, and presents certain limitations. This is evident, in 
terms of its focus on the quantitative characteristics of the online reviews ( $\mathrm{Lu}$ et al., 2013; Zhu \& Zhang, 2010), and the dichotomy approach followed between the positive and negative stance (Floh et al., 2014), overlooking the variability and often complexity of those provided comments. Thus, a better understanding of the effects of the qualitative feature of online reviews seems appropriate.

Online reviews are particularly important for both organisations and consumers when predicting product sales online because they provide them with valuable insights into how consumers' make or alter decisions in either the past or in real time (Duan et al., 2008; Shen et al., 2015). This calls for studies that emphasise the roles of both quantitative and qualitative characteristics when predicting product sales in the online marketplace, given our limited knowledge on the topic.

\subsubsection{Star ratings}

Star ratings impact significantly product sales (Basuroy et al. 2003; Duan et al. 2008), as empirical findings consistently indicate that consumers rely on these sources of information when making purchase decisions (Chevalier \& Mayzlin 2006). Theoreticians exhibit interest in mapping the development and evolution of the review ratings (Godes \& Silva 2012; Moe \& Trusov 2011), in order to explain further how they influence decision making and predictability of future behaviour such as consumer purchases. Practitioners are also interested in better understanding how high star ratings can lead to sales and how this might differ per product category (Bonnet \& Nandan 2011), in order to improve their online presence and communication. The predictive 
value of star ratings' numerical quality diagnostics in relation to factors such as product sales remains in need of further research given the lack of precision and consistency among existing findings (Duan et al., 2008). Further insights might be gained when taking under consideration additional factors such as the qualitative information in customer reviews (Cao et al., 2011; Ludwig et al., 2013).

\subsubsection{No. of people who find reviews helpful (social influence)}

The number of people who finds these reviews helpful is increasing in a very fast pace (Chong et al., 2015). On one hand, users become tired of the plethora of provided information and quite sceptical when it comes through marketer dominated information channels. On the other hand, online reviews from peers appear more trustworthy and influential when making purchase decisions (Tsao, 2014) based on their source and largely non-commercial motivations such as altruism and social presence (Klaus, 2013).

\subsubsection{Rating of most helpful positive reviews}

Positive versus negative reviews are seen of higher perceived helpfulness by consumers, as suggested in literature (Yin et al., 2016), with a few only studies proposing the opposite (Basuroy et al. 2003). The most helpful positive reviews appear to be those that include evidence of real-world use by peers (Kozinets, 2016). Ratings that incorporate experiential information are seen to be better received by consumers when making decision on purchases than solely objective ratings (de Langhe et al., 2016). Subjective and very personal information is also valued as highly helpful, especially when it comes from fellow consumers who appear similar in terms of either 
characteristics or situation to the consumer being informed by the review (Kozinets, 2016). This is attributed to the fact that this way consumers are in better position to assess the suitability of the discussed product in their context of interest, and as a result most likely to go ahead with the purchase. Review helpfulness is further influenced by the product type (Moore 2012). Consumers find more helpful online reviews that include explanations of actions for utilitarian products, and reactions for hedonic products. This in turn, increases consumers' attitude and predictability towards the reviewed product (Moore, 2015) leading to greater positive impact on sales (Chen et al., 2008).

However, when discussing the rating of the most helpful reviews, it might be worth taking under consideration the potential role of the competition effect (Shen et al., 2015). As certain reviewers might choose strategically on which products to post online reviews, as well as what ratings to select, in their attempt to gain consumers' attention, strengthen their reputation, and as a result benefit financially (Hansen \& Haas 2001), they might end up affecting the overall rating, and in turn its predictability on online product sales.

\subsection{Sentiment strength and polarity of online review}

Therefore apart from the quantitative characteristics such as valence and volume of customer reviews, consumers also pay attention to the textual content of online reviews (Chevalier \& Mayzlin, 2006), as seen above. Researchers have argued that the numeric rating of customer reviews may fail to fully reflect the opinions of the reviewers ( $\mathrm{Hu}$ et 
al., 2014). For example, the ratings of reviews are usually not normally distributed and there are likely to be fake reviews, making the average score of ratings less trustworthy (Luca \& Zervas, 2015) and insufficient to provide the accurate information of reviewers' evaluation (Miao et al., 2009). The content of the review can help consumers screen genuine reviews. As Power Reviews suggest, over two-thirds of consumers read four or more reviews before making online purchase (Hu et al., 2014). Therefore, it is important to take review text into account when examining the relationship between reviews and sales as well as the summary statistics (Chevalier \& Mayzlin, 2006).

Based on the textual content of review, sentiment of online review provides rich information for consumers beyond the numeric ratings (Hu et al., 2014). It is a key feature of online review text, delivering reviewer's personal experiences, evaluations and emotions (Chong et al., 2016). It presents reviewer's positive, negative or neutral opinions, or a mixture of them which can influence consumers' cognitive appraisals. Reviewer's subjective feelings can sometimes become difficult to be shown via statistical index such as valence (Hu et al., 2014). For example, the feeling towards a certain product can be complex with some aspects satisfied while others not, and such complex feeling from reviewer cannot be reflected from a numeric rating but rather context-specific explanations. Therefore, sentiment expressed in online review can deliver information that numeric ratings are incapable to fully capture, and thus should also be seen as an important source of cognitive information.

In addition to being information source for consumers' cognitive assessment, sentiment of online review can also lead to emotional contagion (Chong et al., 2016). 
Emotional contagion is where an individual's emotional state gets influenced by another's emotional state, causing emotional convergence (Podoshen, 2013). Customers are exposed to the sentiments and emotions of the reviewers when reading online reviews and such exposure may cause the unconscious change of consumers' emotional states. Previous research indicates that positive and high arousal emotions are likely to stimulate purchases (Somervuori and Ravaja, 2013). Therefore, sentiment of online review may lead to purchase intention unconsciously.

Previous studies usually analyze the sentiment of online review by identifying its polarity (Thelwall et al., 2010). It focuses on the overall evaluation of textual sentiment which is labelled as positive, negative or neutral. However, single polarity cannot fully capture the emotional state of a reviewer given its complexity. To be specific, positive and negative sentiments can be expressed simultaneously yet independently as the products have various features and can be evaluated from different perspectives (Thelwall et al., 2010). It leads to the mixed emotions where two different emotions are co-activated at the same time (Thelwall et al., 2010; Larsen et al., 2001). Berrios et al. (2015) have suggested that mixed emotions can be processed in parallel, supporting the possibility that different emotions in an online review can be processed by potential customers simultaneously. Therefore, measuring both the positive and negative sentiments in one review appears to be an insightful approach to better present the emotional state of a reviewer. In this study, the sentiment of online review is expected to be an important indicator of product sales. Thus, the strength which indicates the levels of orientation (Thelwall et al., 2012; Mostafa, 2013) is measured 
for both positive and negative sentiments in each review, as well as the polarity of the overall sentiment. Details of the measurements are explained in the Section 3.

\subsection{Reviewer identity}

In online marketplace, we have increasingly seen that profile-descriptive information of a reviewer is displayed to other members. Previous studies focusing on the antecedents of perceived value of online reviews have shown that reviewer characteristics can have significant influence on people's attitude towards the review content (Baek et al., 2012; Fang et al., 2016; Liu \& Park, 2015; Racherla \& Friske, 2012).

While the role of reviewer characteristics in affecting the perceived value of review content such as review helpfulness and review quality has been studied in the existing literature, little attention has been paid to their direct influences on customer decisions. Literature from social psychology suggests that source characteristics can affect message recipient's judgment, attitudes and behaviors directly, regardless of the message content (Chaiken \& Maheswaran, 1994; Kang \& Herr, 2006). It is also referred to as messenger bias (Menon \& Blount, 2003) which tends to occur when information is processed in a heuristic manner (Chaiken \& Maheswaran, 1994; Kang \& Herr, 2006). In online environment, reviews for a single product can be numerous, resulting in information overload (Liu \& Park, 2015). Due to the information overload, Forman et al. (2008) have argued that online customers are more likely to process the information heuristically, which in turn promotes online customers' reliance on source cues to make 
decisions. Their results have shown that the identity information disclosed by the reviewer is directly associated with other members' judgment of the products. The study of Ghose et al. (2012) has also supported the positive relationship between disclosure of reviewer identity and product demand without the mediation effect of the review content. Accordingly, we expect that various reviewer characteristics, generated not only by the reviewer themselves but also other customers and the online platform, can affect customer decision directly and independently.

The reviewer profile in online website often contains three kinds of cues: cues generated by other users such as helpful votes, cues generated by system such as reviewer ranking, and cues that are self-created such as real name and profile picture. In this study, we will focus on the three cues of reviewer and investigate in their roles of predicting consumer purchase decisions online.

\subsubsection{Helpful votes of reviewer}

A review will be rated as "helpful" when being perceived as containing valuable information. The number of helpful votes of a reviewer is the sum of helpful votes given by others not only for one review but all the reviews posted by the reviewer, indicating the reviewer's past contributions. Previous literature suggests that compared to the information created by the reviewers themselves, the information generated by others about the reviewer will be considered as more reliable (Xu, 2014). Reviewers endorsed by a lot of others are expected to be responsible and trustworthy. Thus, the presence of peer-recognition system contributes to the trust in reviewer (Ghose et al., 2012). The 
more past helpful votes obtained, the more likely a reviewer will be perceived as a highquality review writer who always provides clear evaluation (Zheng et al., 2013). According to the reviewer's past helpful votes received, customers may extrapolate the credibility of the reviewer directly. Previous studies have shown that reviewer credibility have influences on the perceived credibility of information which further affect people's purchase intention (Xie et al., 2011). However, studies on whether helpful votes of reviewer can lead to better sales directly remain elusive. Here we expect that the helpful votes received by a reviewer which contribute to the source credibility can lead to positive impact on sales.

\subsubsection{Reviewer ranking}

In online environment, information provider's social background and attributes are difficult to be verified as face-to-face conversations are not available, compared with offline environment. Evaluation of the reviewers then has to be based on their past behaviors (Liu \& Park, 2015). Reviewer ranking generated by the system which ranks reviewers based on their past records is thus widely used in online context. It indicates the level of reviewer reputation which enables customers to assess the reviewer credibility and in turn decreases uncertainties and risk faced by customers (Liu \& Park, 2015). By selecting out reviewers who have larger quantity and higher quality of reviews as "top reviewers", it differentiates them from other members and encourages customers' trust in these reviewers (Baek et al., 2012; Filieri, 2015). Zheng et al. (2013) have used reviewer ranking as an indicator of reviewer's social features and shown that 
reviewer with higher ranking tends to have greater influence than others. Previous studies have also shown that reviewer ranking has significant impact on the perceived review quality and review helpfulness (Baek et al., 2012; Filieri, 2015; Zheng et al., 2013). To address the direct relationship between reviewer ranking and product sales, we also include it as a predictor.

\subsubsection{Picture of reviewer}

The profile picture shows what the reviewer looks like. It is believed that the presence of profile photo will reduce discomfort and uncertainty of readers by making them feel like interacting with a real social entity $(\mathrm{Xu}, 2014)$. Prior research suggests that the disclosure of identity information has a positive effect on the establishment of trust to the information source (Xie et al., 2011). And the study of Xu (2014) has supported that the presence of reviewer profile picture in online marketplace will affect affective trust of customers.

While the study of Liu \& Park (2015) has shown that the disclosure of profile picture can increase the credibility of the information source and contribute to the perceived usefulness of review, Racherla \& Friske (2012)'s study has failed to find its significant contribution to usefulness perceptions. In spite of the conflicting results of its effects on review content, limited research has examined its direct influence on purchase behavior. Forman et al. (2008)'s study has shown that the real name disclosed by the reviewer is associated with higher product sales, supporting a direct effect of reviewer identity information on purchase intentions. Following this, we expect that the 
reviewer profile picture also serves as the source cues which assists consumers to form impressions about the reviewer, and can affect their purchase decision directly.

\subsubsection{Picture of products}

Customers tend to seek visual information when making purchase decisions, and pictorial representation of a product can enhance their comprehensive understanding of the products (Lin et al., 2012). Prior research suggests that visual information is positively related to people's memory and attitudes. For example, Shepard (1967) has found that advertisements with photos are recognized and remembered more easily. In a consumer research context, Mitchell \& Olson (1981) have shown that visual information leads to more positive attitudes towards products than verbal information. And MacInnis \& Price (1987) have demonstrated that the imagery information produces positive emotional experience which in turn promotes people's purchase intentions. Studies in internet shopping sites have also supported the positive effects of visual presentation of products offered by online retailer on customer's attitude and purchase intention (Kim \& Lennon, 2008; Park et al., 2005; Then \& DeLong, 1999).

Nowadays, pictures of products can not only be posted by the online retailer but also by the customers. Besides text form, using pictures to convey product features and consumption-related experience is commonly seen in online review. Lin et al. (2012) have shown that eWOM articles with pictures have more significant effects on perceived message quality, credibility, product interest, and purchase intention than the same articles without pictures by using web experiment. It implies that picture in the 
review posted by online customer can play a key role in influencing others' perception and purchase decision. Therefore, we have included it as a predictor to see whether the presence of picture in the review can lead to better demand of a product using real-time data.

\section{Research methods}

\subsection{Big Data architecture}

A big data architecture is used to obtain and store the data. The architecture is scalable and can handle tasks flexibly and efficiently according to the amount of tasks and datasets (Chong et al. 2016). The architecture integrates several open-source server technologies and consists of scalable physical servers (HP DL388p physical servers), virtual machines (64 bit Linux Virtual Machines) and databases (MongoDB) (Ch'ng 2014). Using the architecture, data can be crawled, pre-processed and stored in real time, and the output file contains clean data in prescribed formats.

To capture data we need from Amazon.com, a text file that contains the links to Amazon product list pages is prepared. Having the file, we use asynchronous I/O algorithms to access the webpages of all the products in each product list, process the HTML tags in the webpages, and scrap the targeted details we need. The algorithms are coded with Node.js, and works on a Dell T3600 Tower Workstation. To ensure that the requests from our IP will not be blocked, a recursive mechanism is employed to control the number of $\mathrm{I} / \mathrm{O}$ calls. To find the target information for certain numeric and string data patterns, Regular Expressions are applied to match the patterns. The data extracted 
are stored in MongoDB, a scalable distributed NonSQL database, in real time. When all the links are extracted, the data in our database is converted into Comma Separated Value (csv) file for further analysis.

With slight changes to the algorithms, this big data architecture can be generalized to extract and manage data in other contexts

\subsection{Sentiment analysis}

Sentiment analysis is a systematic approach to identify and measure the sentiment in texts (Chen et al., 2012). In this study, the sentiment analysis is conducted by measuring both the polarity and strength. The sentiment polarity is identified by a Natural Language Processing Application Programming Interface (NLP-API) (Chong et al., 2016). By calculating the probabilities of neutral and polarized sentiment, the API first identify whether the text sentiment is neutral. If the probability of being neutral is larger than 0.5 , the overall sentiment polarity will be marked as neutral. Otherwise, the program will further check the probabilities of being positive and negative. Considering that customers tend to read online reviews one after another, reviews are likely to be processed as a bunch of textual information where the boundary between reviews is vague. Therefore, all the reviews of a certain product are merged into one unit for sentiment analysis. Each product then has a score which takes three values to reflect the aggregate polarity of the reviews: 1 for positive, -1 for negative, and 0 for neutral. The score is used for further hypothesis testing. 
The sentiment strengths are identified using SentiStrength. With SentiStrength, the strengths of both positive sentiment and negative sentiment are measured simultaneously (Thelwall et al., 2010). Each online review is one unit of analysis. SentiStrength checks each word in the review with the lexicon of Linguistic Inquiry and Word Count (LIWC) to identify the strength and corresponding sentiment. The output provides the strength score ranging from 1 to 5 for positive sentiment and -1 to -5 for negative sentiment. The strength scores of positive sentiment and negative sentiment then are averaged respectively for all the reviews of one certain product. Therefore, each product has two average strength scores: one is the average strength of the positive sentiment, and the other is the average strength of the negative sentiment. Unlike sentiment polarity, here we choose to use the strength score of each review rather than the average strength score of all reviews. This is because SentiStrength evaluates the strength of text using the strongest emotional word within the text. If we merge different reviews into one unit, the average score is more likely to be determined by reviews which contain stronger emotional word. In other words, each review is not equally weighted, making the average strength score inappropriate to reflect the full information of all reviews. Table 1 lists the variables extracted and calculated that are used for neural network analysis.

Please insert Table 1 here 


\subsection{Neural Network Analysis}

The main objective of this research is to examine if the variables selected in this study can predict the product sales in an online marketplace. Similar to previous studies, we employed neural network technique to test our model (Leong et al., 2013; Tan et al., 2014). Neural network composed of basic units that are similar to neurons, and this machine technique is based on the idea of human brain (Chiang et al., 2006; Abdi, 1994). The units (referred to as neurons here) linked to each other by connections where the strengths are modifiable due to the learning process or algorithm (Abdi, 1994). These neurons are distributed in three layers - input, hidden and output. The input neuron is given a synaptic weight which will then be passed to the hidden nodes in the hidden layer, and finally they are transformed into an output value using activation functions (e.g. sigmoid) (Tan et al., 2014). The synaptic weights of the neural connections will go through an iterative training and learning process whereby the outcome knowledge will then be stored for predictive purpose (Chong et al., 2016).

Neural network' applications in information systems and operations management have been gaining interests in recent years, and have been used to predict different areas such as mobile commerce adoption (Chong, 2013), mobile learning (Tan et al., 2014) as well as consumer product demand (Chong et al., 2016). Similar to Chong et al. (2015), this research employs neural network to predict the sales rank of product sales in an online marketplace. However, the predictors used are different, and in particular, this research aims to investigate the role of online review sentiment as a 
predictor of online marketplace, a predictor which has been sparely examined in previous studies.

The neural network technique employed in this study is the multilayer perceptron (MLP). One of the main reason why the MLP was chosen is that MLP is non parametric and therefore it has no restricted assumption on the variables (Chong et al., 2016). The model can also be examined for both linear and non-linear relationships given that MLP does not have a pre-definition of the relationships, and can be trained to accurately generalize new and unforeseen data (Chong et al., 2006). Figure 1 shows an example of MLP neural network employed in this study.

Please insert Figure 1 here

\section{Methodology}

Similar to studies in $\mathrm{Hu}$ et al. (2014) and Chong et al. (2016), we used data from Amazon.com for this study. Electronic products such as computers, camera, televisions etc. have been selected for this study. The reason for choosing electronic products is similar to Chong et al. (2016) whereby these products tend to have shorter product shelf lives, and therefore we can examine how the different variables related to reviews and sentiments can predict the sales of the products. 12188 electronic data were randomly selected for this study. However, out of the 12188 data, only 6000 data were found to have review comments. Given that the some of the main predictors used in this study include sentiment strengths and polarity of the reviews, we only included the 6000 data 
that contains online reviews. Thus in this study, the predictors used include variables related to online reviews such as review ratings (valance), number of people who find reviews helpful (social influence), rating of the most helpful positive reviews, sentiment strengths of reviews, and variables related to reviewer identify such as helpful votes of reviewers, reviewer ranking and picture of reviewer. We also include whether a picture of the product is available to customers as this will influence users' perception of the product. Product sales in this study is measured based on sales rank and this approach is similar to existing studies conducted by Hu et al. (2014) and Chong et al. (2016).

\subsection{Validations of Neural Networks}

MLP training algorithm is applied to train our neural network models. In order to avoid over-fitting of the model, cross validations were conducted. Similar to existing studies by Tan et al. (2014), we increased the number of hidden nodes and examine the errors of the neural network. When the errors do not increase, the ideal number of hidden nodes has have been reached. The number of hidden nodes in this study is four. Thus the neural network model for this study includes12 predictors, four hidden nodes, and one output variable.

SPSS 20 was used to perform our neural network analysis. We selected the sigmoid function as the activation function for this study. A tenfold cross validation was performed whereby 70 percent of our data was used to train the neural network 
while the remaining 30 percent was used to test the prediction accuracy. Table 2 shows the relative errors for each of the ten training and testing data sets.

Please insert Table 2 here

The average training errors for the training data was 0.964 while the testing was 0.958. We found from conducting T-Test that there is no significant difference between the errors found in the training and testing datasets.

\subsection{Sensitivity analyses and Regression Analysis}

In order to fine out the important predictors for this study, sensitivity analyses using SPSS 20 was performed on the data. Sensitivity analyses was calculated based on the average of the predictors over ten networks, and this approach is consistent with Chong et al. (2016) and Tan et al. (2014). The predictors' importance is a measurement of how much the network model predicted value changes for different values of the input variables. We averaged the input variables' importance over ten networks, and expressed the values as percentages. Table 3 shows the result of the sensitivity analysis.

Please insert Table 3 here

Based on the result, all predictors are found to be relevant in the neural networks. Based on the average results, important predictors in the model include helpful votes of reviewers, picture of the reviewer, review volume and number of people who find reviews helpful are the most important predictors in the model. On 
the other hand, the review rating (valance), pictures of the products, reviewer ranking, ratings of the most helpful positive reviews and sentiment polarity were found to be relevant, but less importance compared to the other predictors.

Although neural network was able to allow us to understand that all variables used in this study are good predictors of product sales, we are not able to understand the causal relationships between the predictors and product sales. Therefore in order to understand the relationships, we adapted the MRA-Neural Network approach by Sim et al. (2014). However, contrary to their approach, we believe a Neural Network first approach, followed by Multiple Regression Analysis (MRA) would allow us to understand our model instead of MRA and then Neural Network as conducted by Sim et al. (2014). Neural network would allow us to select only the important predictors, and then use them as input to MRA so that we know the relationships of the predictors and output variable which cannot be explained by MRA. Given that all input variables are found to be predictors, they are all used as inputs in our MRA. Our MRA result shows that among all the predictors, the following predictors, have a significant relationship with product sales: Review Valence $(\mathrm{P}<0.05)$, Sentiment Strengths (Positive) $(\mathrm{P}<0.001)$, Sentiment Polarity $(\mathrm{P}<0.05)$, Helpful votes of reviewers $(\mathrm{P}<0.05)$, Picture of Reviewer $(\mathrm{P}<0.001)$, Picture of Products $(\mathrm{P}<0.05)$ and Review Volume $(\mathrm{P}<0.05)$

\section{Discussions}

This study aims to examine if variables related to online reviews, reviewers identify, 
sentiments, and picture of products can predict the sales of products in an online marketplace. In general, our result found that the variables proposed are all important predictors of online sales, with variables related to reviewers such as helpful votes of reviewers and picture of reviewers found to be the 2 most important predictors. This result is interesting and it shows that it is not the content of the reviews that are the most important predictors, but rather, it is other users' voting of how helpful the reviewer is. This confirms existing studies conducted by Ghose et al. (2012) and Zheng et al. (2013) where reviewers who are endorsed by peers and having a peer recognition system can create more trust by users, and thus increasing product sales. Furthermore, our MRA result also shows that helpful votes of reviewers and picture of reviewers both have a positive and significant relationship with product sales.

Similar to existing studies such as those conducted by Lu et al. (2013), Duan et al. (2008) and Chong et al. (2016), this study also found that review volume is an important predictor of product sales. Review volume is also found to have a significant and positive relationship with product sales. Thus products that received more review comments is a good predictor of product sales, and it can also influence the sales of the products in an online marketplace.

Review valence although is found not to be the most important predictors of product sales, it has a significant and positive relationship with sales based on our MRA result. Thus users are still influenced by the persuasive effect of online review when purchasing a product online (Cheung and Thadani, 2012). This study extends the understanding on Chong et al. (2016) which found that review valence is a predictor of 
product sales, but the paper was not able to explain if causal relationship existing between review valence and product sales. This study confirms this relationship.

This study extends the study by Chong et al. (2016) by not only examining the polarity of the review text sentiments, and we also further examined the strengths of the negative and positive sentiments. In general, we found that sentiment strengths are good predictors of product sales as they are ranked as the 5th and 6th most important predictors in our neural network. Furthermore, positive review strength has a positive relationship with product sales. Our result shows that the strength of positive comments is able to drive the sales of the products online. This contradicts with some past studies such as those by Cui et al. (2012) which found that negative review comments are more likely to play a bigger role in affecting a user's purchasing decision than positive review comments. Despite not being a strong predictor in our neural network, sentiment polarity has a significant and positive relationship with product sales. Thus consistent with the findings from the sentiment strengths of positive reviews, we found that products that have more positive reviews are going to have better sales.

Lastly, our result showed that picture of products is a predictor of product sales, but is not as important as other variables related to online reviews. Nevertheless, it was found to have a positive and significant relationship with product sales, and therefore confirming the suggestion from Lin et al. (2012) which stated that having pictorial representation of the product can help consumers to understand the products. This is important especially when electronic products used in this study are search 
products, thus having a picture of the products will allow users to evaluate the electronic products before purchasing.

\section{Implications and Conclusions}

This research examines what predicts the sales of products online using neural network, as well as examining the causal relationship between the predictors and product sales using MRA. A big data architecture was designed to capture the data from an online marketplace, and sentiment analysis was conducted on the review contents. One of the key contributions of this study is to include the sentiment strengths of the online reviews in predicting the sales of products in an online marketplace.

This study has several important implications. First, this study employed a big data architecture to extract data from an online marketplace. We employed special sets of asynchronous algorithms to extract data and pre-process them in real time. This sample size allows us to employ neural network to predict the online product sales. This data architecture can be extended to extract other online marketplace or social media websites with review contents. As the data is quite large, we first employed neural network to understand if the input variables used in this study are predictors of online sales. Upon determining that all the variables used are predictors, the variables are also tested in MRA to help understand the causal relationships between the predictors and product sales.

Second, this research found that information related to the online reviews such as the valance, volume, number of people who find the review helpful and rating of the 
most helpful positive reviews to be important predictors of online sales. Furthermore, among these variables related to online reviews, review volume and review valance have significant and positive relationships with the sales of products. Thus online shops should pay careful attentions to online review by customers on their products. A product that received more reviews and better ratings may be more in demand by customers, and while those with poor reviews should be taken into serious considerations and understand why are customers dissatisfied with the products.

Third, this study also found that some attributes related to the reviewers are good predictors of online sales. For example, helpful votes of reviewers and having a picture of a reviewer can predict the sales of product. We also found these variables to have positive and significant relationships with product sales. Therefore, online sellers or online marketplace can encourage active reviewers to include a picture of themselves to increase trust. In the popular online marketplace owned by Alibaba such as Taobao, trust by providing verified identities of reviewers, sellers and buyers are one factor why it is one of the most successful online e-marketplace in China (Oberholzer-Gee and Wulf, 2009). The reviewers' trustworthiness can also be increased by the helpful votes of reviewers. Thus future e-commerce websites that have online reviews can include feature which allows users to vote the helpfulness of the reviewers. This helps users to differentiate reviewers who are voted to be helpful and those that are perceived to be less helpful, which can be important as there could be too many reviewers posting online reviews in popular online marketplace. 
Lastly, our study further examined the role of review sentiments and how they predict and influence product sales. This study extended previous studies (e.g. Chong et al., 2016) on online review sentiments as it found that positive sentiment strengths and sentiment polarity are important product sales predictors, as well as having significant relationships with product sales. Thus for online sellers, although understanding sentiments such as whether they are positive, negative or neutral are useful, exploring these sentiments such as their strengths (e.g. how positive is the positive sentiment?) can allow us to understand better reviewers and customers' perceptions of the products.

\section{$7 \quad$ Limitations and future studies}

There are several limitations for this study which future studies can address. Firstly, this study only examined electronic products. Future studies can explore different types of products and also compare if the variables used in this study predict differently for different product types. Secondly, although we have designed a big data architecture and extracted the data, due to the fact that many product pages do not have review comments, we were only able to select 6000 sample data for our study. Future studies can collect more data, as well as extending this to other e-marketplaces. A cross country comparison studies on different online e-marketplace such as Amazon and Taobao could also offer us more insights as to whether users from different countries are influenced by reviews differently. 


\section{Acknowledgements}

All authors contributed equally to this paper 
References

Abdi, H. (1994). A neural network primer. Journal of Biological Systems, 2(03), pp.247-281.

Ashley, C. and T. Tuten. (2015). Creative Strategies in Social Media Marketing: An exploratory Study of Branded Social Content and Consumer Engagement. Psychology \& Marketing, 32(1), 15-27.

Baek, H., Ahn, J., \& Choi, Y. (2012). Helpfulness of Online Consumer Reviews: Readers' Objectives and Review Cues. International Journal of Electronic Commerce, 17(2), 99-126.

Bakos, Y., and C. Dellarocas. (2011). Cooperation without enforcement? A comparative analysis of litigation and online reputation as quality assurance mechanisms. Management Science, 57(11), 1944-1962.

Basuroy, S., Chatterjee, S., and S.A. Ravid. (2003). How critical are critical reviews? The box office effects of film critics, star power, and budgets. Journal of Marketing, 67(4), 103-117.

Berrios, R., Totterdell, P., \& Kellett, S. (2015). Eliciting mixed emotions: a metaanalysis comparing models, types, and measures. Frontiers in Psychology, 6.

Bonnet, D. and N. Priyank. (2011). Transform to the Power of Digital: Digital Transformation as a Driver of Corporate Performance. report, Capgemini Consulting.

Cao, Q., Wenjing, D., and G. Qiwei. (2011). Exploring Determinants of Voting for the 'Helpfulness' of Online User Reviews: A Text Mining Approach. Decision Support Systems, 50(2), 511-21.

Ch'ng, E. (2014). The value of using big data technology in computational social science, Proceedings of the 3rd ASE Big Data Science Conference, Tsinghua University Beijing China, August 4-7, pp. 1-4.

Chaiken, S., \& Maheswaran, D. (1994). Heuristic processing can bias systematic processing: effects of source credibility, argument ambiguity, and task importance on attitude judgment. Journal of Personality and Social Psychology, 66(3), 460-473. 
Chen, H., Chiang, R. H., \& Storey, V. C. (2012). Business Intelligence and Analytics: From Big Data to Big Impact. MIS Quarterly, 36(4), 1165-1188.

Chen, P.Y., Dhanasobhon, S., and M.D. Smith. (2008). All Reviews Are Not Created Equal: The Disaggregate Impact of Reviews and Reviewers at Amazon.com. working paper, Carnegie Mellon University, http://ssrn.com/abstract¹/4918083.

Cheung, C.M., Lee, M.K. and Rabjohn, N. (2008). The impact of electronic word-ofmouth: The adoption of online opinions in online customer communities. Internet Research, 18(3), pp.229-247.

Chevalier, J. A. and Mayzlin, D. (2006). The Effect of Word of Mouth on Sales: Online Book Reviews. Journal of Marketing Research, 43(3), pp. 345-354. Chong, A. Y. L., Li, B., Ngai, E. W., Ch'ng, E., \& Lee, F. (2016). Predicting online product sales via online reviews, sentiments, and promotion strategies: A big data architecture and neural network approach. International Journal of Operations \& Production Management, 36(4), 358-383.

Chong, A. Y.-L., Ch'ng, E., Liu, M. J., \& Li, B. (2015). Predicting consumer product demands via Big Data: the roles of online promotional marketing and online reviews. International Journal of Production Research, 1-15.

Chong, A.Y.L. (2013). Predicting m-commerce adoption determinants: A neural network approach. Expert Systems with Applications, 40(2), pp.523-530.

Clemons, E.K., Gao, G.G. and L.M. Hitt. (2006). When online reviews meet hyperdifferentiation: a study of the craft beer industry. Journal of Management Information Systems, 23(2), 149-171.

Croom, S. R. (2005). The impact of e - business on supply chain management. International Journal of Operations \& Production Management, 25(1), 55-73. de Langhe, B., Fernbach, P. M. and D. R. Lichtenstein. (2016). Navigating by the Stars: Investigating the Actual and Perceived Validity of Online User Ratings. Journal of Consumer Research.

Duan, W., Gu, B. and Whinston, A.B. (2008). The dynamics of online word-of-mouth and product sales - An empirical investigation of the movie industry.Journal of retailing, 84(2), pp.233-242 
Duan, W., Gu, B., \& Whinston, A. B. (2008). Do online reviews matter? - An empirical investigation of panel data. Decision Support Systems, 45(4), 10071016.

Fang, B., Ye, Q., Kucukusta, D., \& Law, R. (2016). Analysis of the perceived value of online tourism reviews: Influence of readability and reviewer characteristics. Tourism Management, 52, 498-506.

Filieri, R. (2015). What makes online reviews helpful? A diagnosticity-adoption framework to explain informational and normative influences in e-WOM. Journal of Business Research, 68(6), 1261-1270. http://doi.org/10.1016/j.jbusres.2014.11.006

Floyd, K., Freling, R., Alhoqail, S., Young H. C., and T. Freling. (2014). How Online Product Reviews Affect Retail Sales: A Meta-Analysis. Journal of Retailing, 90(2), 217-32.

Forman, C., Ghose, A., \& Wiesenfeld, B. (2008). Examining the relationship between reviews and sales: The role of reviewer identity disclosure in electronic markets. Information Systems Research, 19(3), 291-313.

Ghose, A., Ipeirotis, P. G., \& Li, B. (2012). Designing Ranking Systems for Hotels on Travel Search Engines by Mining User-Generated and Crowdsourced Content. Marketing Science, 31(3), 493-520.

Godes, D., and D. Mayzlin. (2004). Using Online Conversations to Study Word-ofMouth Communication. Marketing Science, 23 (4), 545-60.

Godes, D., and J. Silva. (2012). Sequential and Temporal Dynamics of Online Opinion. Marketing Science, 31(3), 448-473.

Hansen, M. T., and M. R. Haas. (2001). Competing for Attention in Knowledge Markets: Electronic Document Dissemination in a Management Consulting Company. Administrative Science Quarterly, 46(1), 1-28.

Hu, N., Koh, N. S., \& Reddy, S. K. (2014). Ratings lead you to the product, reviews help you clinch it? The mediating role of online review sentiments on product sales. Decision support systems, 57, 42-53. 
Hu, N., Koh, N.S. and Reddy, S.K. (2014). Ratings lead you to the product, reviews help you clinch it? The mediating role of online review sentiments on product sales. Decision support systems, 57, pp.42-53

Huang, Q., Chen, X., Ou, C. X., Davison, R. M., \& Hua, Z. (2015). Understanding buyers' loyalty to a $\mathrm{C} 2 \mathrm{C}$ platform: the roles of social capital, satisfaction and perceived effectiveness of e-commerce institutional mechanisms. Information Systems Journal, n/a-n/a.

Jensen, M.L., Averbeck, J.M., Zhang, Z. and K. Wright. (2013). Credibility of Anonymous Online Product Reviews: A Language Expectancy Perspective. Journal of Management Information Systems, 30(1), 293-323.

Kang, Y., \& Herr, P. M. (2006). Beauty and the Beholder: Toward an Integrative Model of Communication Source Effects. Journal of Consumer Research, 33(1), 123-130.

Kim, M., \& Lennon, S. (2008). The Effects of Visual and Verbal Information on Attitudes and Purchase Intentions in Internet Shopping. Psychology \& Marketing, 25(2), 146-178.

Klaus, P. (2013). The Case of Amazon.com: Towards a Conceptual Framework of Online Customer Service Experience (OCSE) Using the Emerging Consensus Technique (ECT). Journal of Services Marketing, 27 (6), 443-57.

Koh, S. C. L., Demirbag, M., Bayraktar, E., Tatoglu, E., \& Zaim, S. (2007). The impact of supply chain management practices on performance of SMEs. Industrial Management \& Data Systems, 107(1), 103-124.

Kozinets R., Hemetsberger, A., and J. Schau. (2008). The wisdom of consumer crowds. Journal of Macromarketing, 28(4), 339-54.

Kozinets, R. (2016). Amazonian Forests and Trees: Multiplicity and Objectivity in Studies of Online Consumer-Generated Ratings and Reviews, A Commentary on de Langhe, Fernbach, and Lichtenstein. Journal of Consumer Research, 42 (6), 834-839. 
Kumar, N. and Benbasat, I. (2006). The Influence of Recommendations and Consumer Reviews on Evaluations of Websites. Information Systems Research, 17 (4), 425-39.

Lambert, D. M., \& Cooper, M. C. (2009). Issues in Supply Chain Management. Industrial Marketing Management, 29(1), 65-83.

Larsen, J. T., McGraw, A. P., \& Cacioppo, J. T. (2001). Can people feel happy and sad at the same time?. Journal of personality and social psychology, 81(4), 684.

Lee, H. L. H., \& Whang, S. (2000). Information sharing in a supply chain. International Journal of Manufacturing Technology. http://doi.org/10.1016/j.omega.2014.08.001

Leong, L.Y., Hew, T.S., Tan, G.W.H. and Ooi, K.B. (2013). Predicting the determinants of the NFC-enabled mobile credit card acceptance: A neural networks approach. Expert Systems with Applications, 40(14), pp.5604-5620.

Lin, T. M. ., Lu, K.-Y., \& Wu, J.-J. (2012). The Effects of Visual Information in eWOM Communication. Journal of Research in Interactive Marketing, 6(1), $7-26$.

Liu, Y. (2006). Word of Mouth for Movies: Its Dynamics and Impact on Box Office Revenue. Journal of Marketing, 70(3), 74-89.

Liu, Z., \& Park, S. (2015). What makes a useful online review? Implication for travel product websites. Tourism Management, 47, 140-151.

Lu, X., Ba, S., Huang, L. and Feng, Y. (2013). Promotional marketing or word-ofmouth? Evidence from online restaurant reviews. Information Systems Research, 24(3), pp.596-612.

Lu, X., Ba, S., Huang, L. and Y. Feng. (2013). Promotional marketing or word-ofmouth? Evidence from online restaurant reviews. Information Systems Research, 24 (3), 596-612.

Luca, M., \& Zervas, G. (2015). Fake it till you make it: Reputation, competition, and Yelp review fraud. Harvard Business School NOM Unit Working Paper, (14-006). 
Ludwig, S., Ruyter, K., Friedman, M., Bruggen, E.C., Wetzels, M. and G. Pfann. (2013). More than words: the influence of affective content and linguistic style matches in online reviews on conversion rates. Journal of Marketing, 77, 87103.

MacInnis, D. J., \& Price, L. L. (1987). The Role of Imagery in Information Processing: Review and Extensions. Journal of Consumer Research, 13(4), $473-491$.

Menon, T., \& Blount, S. (2003). the Messenger Bias: a Relational Model of Knowledge Valuation. Research in Organizational Behavior, 25(03), 137-186. http://doi.org/10.1016/S0191-3085(03)25004-8

Miao, Q., Li, Q., \& Dai, R. (2009). AMAZING: A sentiment mining and retrieval system. Expert Systems with Applications, 36(3), 7192-7198.

Mitchell, A. a, \& Olson, J. C. (1981). Are Product Attribute Beliefs the Only Mediator of Advertising Effects on Brand Attitude? Journal of Marketing Research, 18(3), 318-332.

Moe, W. W., and M. Trusov. (2011). The Value of Social Dynamics in Online Product Ratings Forums. Journal of Marketing Research, 48 (May), 444-56.

Moore, S. (2015). Attitude Predictability and Helpfulness in Online Reviews: The role of explained actions and reactions. Journal of Consumer Research, 42, 30-44.

Moore, S. G. (2012). Some Things Are Better Left Unsaid: How Word of Mouth Influences the Storyteller. Journal of Consumer Research, 38 (6), 1140-54.

Mostafa, M. M. (2013). More than words: Social networks' text mining for consumer brand sentiments. Expert Systems with Applications, 40(10), 4241-4251.

Mudambi, S. M. and D. Schuff. (2010). What Makes a Helpful Online Review? A Study of Customer Reviews on Amazon.com. MIS Quarterly, 34 (1), 185200.

Oberholzer-Gee, Felix, and Julie M. Wulf. "Alibaba's Taobao (A)." Harvard Business School Case 709-456, January 2009.

Pan, Y., \& Zhang, J. Q. (2011). Born Unequal: A Study of the Helpfulness of UserGenerated Product Reviews. Journal of Retailing, 87(4), 598-612. 
Park, D.-H., Lee, J., \& Han, I. (2007). The Effect of On-Line Consumer Reviews on Consumer Purchasing Intention: The Moderating Role of Involvement. International Journal of Electronic Commerce, 11(4), 125-148.

Park, J., Lennon, S. J., \& Stoel, L. (2005). On-line product presentation: Effects on mood, perceived risk, and purchase intention. Psychology and Marketing, 22(9), 695-719.

Podoshen, J. S. (2013). Dark tourism motivations: Simulation, emotional contagion and topographic comparison. Tourism Management, 35, 263-271.

Racherla, P., \& Friske, W. (2012). Perceived "usefulness" of online consumer reviews: An exploratory investigation across three services categories. Electronic Commerce Research and Applications, 11(6), 548-559.

Rahman, Z. (2004). Use of Internet in supply chain management: a study of Indian companies. Industrial Management \& Data Systems, 104(1), 31-41.

Shen, W., Hu Y.J., and J.R. Ulmer. (2015). Competing for Attention: An Empirical Study of Online Reviewers' Strategic Behavior. MIS Quarterly, 39 (3), 683 696.

Shepard, R. N. (1967). Recognition Memory for Words, Sentences, and Pictures. Journal of Verbal Learning and Verbal Behavior, 6, 156-163.

Sim, J.J., Tan, G.W.H., Wong, J.C., Ooi, K.B. and Hew, T.S. (2014). Understanding and predicting the motivators of mobile music acceptance-a multi-stage MRA-artificial neural network approach. Telematics and informatics, 31(4), pp.569-584.

Simonson, I. (2015). Mission (Largely) Accomplished: What's Next for Consumer BDT-JDM Researchers. Journal of Marketing Behavior, 1(9), 35.

Simonson, I., and E. Rosen. (2014). Absolute Value: What Really Influences Customers in the Age of (Nearly) Perfect Information, New York: HarperCollins.

Somervuori, O., \& Ravaja, N. (2013). Purchase behavior and psychophysiological responses to different price levels. Psychology \& Marketing, 30(6), 479-489. 
Sparks, B. a., \& Browning, V. (2011). The impact of online reviews on hotel booking intentions and perception of trust. Tourism Management, 32(6), 1310-1323. http://doi.org/10.1016/j.tourman.2010.12.011

Tan, G.W.H., Ooi, K.B., Leong, L.Y. and Lin, B. (2014). Predicting the drivers of behavioral intention to use mobile learning: A hybrid SEM-Neural Networks approach. Computers in Human Behavior, 36, pp.198-213.

Tang, T.Y., Fang, E.E. and W. Feng. (2014). Is neutral really neutral? The effects of neutral user-generated content on product sales. Journal of Marketing, 78(3), 41-58.

Thelwall, M., Buckley, K., \& Paltoglou, G. (2012). Sentiment strength detection for the social web. Journal of the American Society for Information Science and Technology, 63(1), 163-173.

Thelwall, M., Buckley, K., Paltoglou, G. Cai, D., \& Kappas, A. (2010). Sentiment strength detection in short informal text. Journal of the American Society for Information Science and Technology, 61(12), 2544-2558.

Themistocleous, M., Irani, Z., \& Love, P. E. D. (2004). Evaluating the integration of supply chain information systems: A case study. European Journal of Operational Research, 159(2 SPEC. ISS.), 393-405.

Then, N., \& DeLong, M. (1999). Apparel Shopping on the Web. Journal of Family and Consumer Science.

Tirunillai, S., and Tellis, G.J. (2012). Does chatter really matter? Dynamics of usergenerated content and stock performance. Marketing Science, 31 (2), 198-215.

Tsao, W.C. (2014). Which type of online review is more persuasive? The influence of consumers reviews and critic ratings on moviegoers. Electronic Commerce Research, 14, 559-583.

Wenjing, D., Gu, B., and A. B. Whinston. (2008). Do Online Reviews Matter? An Empirical Investigation of Panel Data. Decision Support Systems, 45(4),10071016.

Xie, H., Miao, L., Kuo, P. J., \& Lee, B. Y. (2011). Consumers' responses to ambivalent online hotel reviews: The role of perceived source credibility and 
pre-decisional disposition. International Journal of Hospitality Management, $30(1), 178-183$.

Xinxin, L., and L.M. Hitt. (2010). Price Effects in Online Product Reviews: An Analytical Model and Empirical Analysis. MIS Quarterly, 34(4), 809-831.

$\mathrm{Xu}, \mathrm{Q}$. (2014). Should i trust him? the effects of reviewer profile characteristics on eWOM credibility. Computers in Human Behavior, 33, 136-144.

Ye, Q., Law, R., Gu, B., \& Chen, W. (2011). The influence of user-generated content on traveler behavior: An empirical investigation on the effects of e-word-ofmouth to hotel online bookings. Computers in Human Behavior, 27(2), 634639.

Yin, D., Mitra, S., and H. Zhang. (2016). When Do Consumers Value Positive vs. Negative Reviews? An Empirical Investigation of Confirmation Bias in Online Word of Mouth. Information Systems Research, 27(1), 131-144.

Zheng, X., Zhu, S., \& Lin, Z. (2013). Capturing the essence of word-of-mouth for social commerce: Assessing the quality of online e-commerce reviews by a semi-supervised approach. Decision Support Systems, 56(1), 211-222.

Zhu, F., \& Zhang, X. (Michael). (2010). Impact of Online Consumer Reviews on Sales: The Moderating Role of Product and Consumer Characteristics. Journal of Marketing, 74(2), 133-148. 
Table 1 Summary of Variables

\begin{tabular}{|c|c|c|}
\hline Variables & Description & Operationalization \\
\hline Sales Rank & $\begin{array}{l}\text { Amazon's Best Sellers } \\
\text { Rank of the product }\end{array}$ & $\begin{array}{l}\text { For a product, we take the Best Sellers } \\
\text { Rank of the product, extracted directly } \\
\text { from Amazon product webpage, the } \\
\text { higher the sales are, the smaller the rank } \\
\text { is }\end{array}$ \\
\hline $\begin{array}{l}\text { Review } \\
\text { volume }\end{array}$ & $\begin{array}{l}\text { otal number of online } \\
\text { eviews of a product }\end{array}$ & $\begin{array}{l}\text { For a product, we take the total number } \\
\text { of all its online reviews, extracted } \\
\text { directly from Amazon product webpage }\end{array}$ \\
\hline Star rating & Star rating of a product & $\begin{array}{l}\text { For a product, we take the star rating of } \\
\text { it calculated by Amazon using its } \\
\text { machine learned model, extracted } \\
\text { directly from Amazon product webpage, } \\
\text { one-digit decimal from } 0 \text { to } 5\end{array}$ \\
\hline $\begin{array}{l}\text { No. of } \\
\text { people who } \\
\text { find } \\
\text { reviews } \\
\text { helpful }\end{array}$ & $\begin{array}{l}\text { Average number of people } \\
\text { who found reviews helpful } \\
\text { to them }\end{array}$ & $\begin{array}{l}\text { For a product, we collect the number of } \\
\text { helpful votes (number of people who } \\
\text { found the review helpful) of each review } \\
\text { we extract, and then take the average of } \\
\text { the numbers, calculated }\end{array}$ \\
\hline $\begin{array}{l}\text { Rating of } \\
\text { most } \\
\text { helpful } \\
\text { positive } \\
\text { reviews }\end{array}$ & $\begin{array}{l}\text { Star rating of the positive } \\
\text { review of a product with } \\
\text { the highest agreement on } \\
\text { helpfulness }\end{array}$ & $\begin{array}{l}\text { For a product, we take the star rating of } \\
\text { the Top Positive Review, extracted } \\
\text { directly from Amazon product webpage }\end{array}$ \\
\hline $\begin{array}{l}\text { Positive } \\
\text { sentiment } \\
\text { strength }\end{array}$ & $\begin{array}{l}\text { Average degree of positive } \\
\text { sentiment of extracted } \\
\text { online reviews }\end{array}$ & $\begin{array}{l}\text { For a product, we calculate the degree of } \\
\text { positive sentiment of each review we } \\
\text { extract, and then take the average of the } \\
\text { degrees, calculated, from } 1 \text { to } 5\end{array}$ \\
\hline $\begin{array}{l}\text { Negative } \\
\text { sentiment } \\
\text { strength }\end{array}$ & $\begin{array}{l}\text { Average degree of negative } \\
\text { sentiment of extracted } \\
\text { online reviews }\end{array}$ & $\begin{array}{l}\text { For a product, we calculate the degree of } \\
\text { negative sentiment of each review we } \\
\text { extract, and then take the average of the } \\
\text { degrees, calculated, from }-1 \text { to }-5\end{array}$ \\
\hline $\begin{array}{l}\text { Sentiment } \\
\text { polarity }\end{array}$ & $\begin{array}{l}\text { Overall sentiment } \\
\text { orientation of reviews }\end{array}$ & $\begin{array}{l}\text { For a product, we classify the polarity of } \\
\text { sentiment of all reviews we extract as a } \\
\text { whole, calculated, positive sentiment as } \\
1 \text {, negative as }-1 \text {, neutral as } 0\end{array}$ \\
\hline $\begin{array}{l}\text { Helpful } \\
\text { votes of } \\
\text { reviewer }\end{array}$ & $\begin{array}{l}\text { Average number of people } \\
\text { who found a reviewer's } \\
\text { reviews helpful }\end{array}$ & $\begin{array}{l}\text { For the reviews we extract of a product, } \\
\text { we collect the number of helpful votes of } \\
\text { each reviewer from his or her profile } \\
\text { page, and then take the average of the } \\
\text { numbers, calculated }\end{array}$ \\
\hline Reviewer & ranking & For the reviews we extract of a product, \\
\hline
\end{tabular}




\begin{tabular}{l|l|l}
\hline ranking & reviewers & $\begin{array}{l}\text { we collect the reviewer ranking of each } \\
\text { reviewer from his or her profile page, } \\
\text { and then take the average of the } \\
\text { rankings, calculated }\end{array}$ \\
\hline $\begin{array}{l}\text { Picture of } \\
\text { reviewer }\end{array}$ & $\begin{array}{l}\text { Total number of reviewers } \\
\text { with profile picture }\end{array}$ & $\begin{array}{l}\text { For the reviews we extract of a product, } \\
\text { if the reviewer has a profile image we } \\
\text { code it as 1, no profile image as 0, and } \\
\text { then sum up all the values, calculated }\end{array}$ \\
\hline $\begin{array}{l}\text { Picture of } \\
\text { products }\end{array}$ & $\begin{array}{l}\text { Total number of reviews } \\
\text { with pictures }\end{array}$ & $\begin{array}{l}\text { For the reviews we extract of a product, } \\
\text { if the review content contains a picture } \\
\text { we code it as 1, no picture as 0, and then } \\
\text { sum up all the values, calculated }\end{array}$ \\
\hline
\end{tabular}


Table 2 Validation Results

\begin{tabular}{|c|c|c|}
\hline Network & Training & Testing \\
\hline 1 & 0.961 & 0.951 \\
\hline 2 & 0.976 & 0.974 \\
\hline 3 & 0.964 & 0.962 \\
\hline 4 & 0.963 & 0.956 \\
\hline 5 & 0.963 & 0.968 \\
\hline 6 & 0.966 & 0.953 \\
\hline 7 & 0.961 & 0.955 \\
\hline 8 & 0.965 & 0.918 \\
\hline 9 & 0.959 & 0.970 \\
\hline 10 & 0.966 & 0.969 \\
\hline Mean & 0.964 & 0.958 \\
\hline SD & 0.00443 & 0.015239 \\
\hline
\end{tabular}


Table 3 Sensitivity Analysis

\begin{tabular}{|c|c|c|c|c|c|c|c|c|c|c|c|}
\hline & N1 & $\mathbf{N 2}$ & $\mathbf{N 3}$ & N4 & N5 & N6 & N7 & N8 & N9 & N10 & $\begin{array}{c}\text { Importance } \\
(\%)\end{array}$ \\
\hline Helpful Votes of Reviewers & 0.099 & 0.166 & 0.232 & 0.123 & 0.286 & 0.164 & 0.102 & 0.157 & 0.078 & 0.132 & $15 \%$ \\
\hline Picture of Reviewer & 0.177 & 0.098 & 0.136 & 0.136 & 0.066 & 0.126 & 0.177 & 0.093 & 0.154 & 0.133 & $13 \%$ \\
\hline Review Volume & 0.075 & 0.203 & 0.059 & 0.14 & 0.152 & 0.101 & 0.122 & 0.142 & 0.158 & 0.134 & $13 \%$ \\
\hline No. of People who find reviews helpful & 0.144 & 0.101 & 0.109 & 0.143 & 0.062 & 0.097 & 0.127 & 0.134 & 0.106 & 0.155 & $12 \%$ \\
\hline Sentiment strength (Positive) & 0.053 & 0.119 & 0.1 & 0.095 & 0.089 & 0.119 & 0.092 & 0.093 & 0.103 & 0.069 & $9 \%$ \\
\hline Sentiment strength (Negative) & 0.122 & 0.04 & 0.137 & 0.097 & 0.069 & 0.119 & 0.074 & 0.077 & 0.076 & 0.059 & $9 \%$ \\
\hline Review Valence & 0.134 & 0.057 & 0.052 & 0.059 & 0.083 & 0.07 & 0.13 & 0.099 & 0.064 & 0.095 & $8 \%$ \\
\hline Picture of Products & 0.063 & 0.077 & 0.041 & 0.077 & 0.071 & 0.065 & 0.092 & 0.059 & 0.123 & 0.101 & $8 \%$ \\
\hline Reviewer Ranking & 0.091 & 0.071 & 0.045 & 0.064 & 0.065 & 0.08 & 0.055 & 0.062 & 0.07 & 0.074 & $7 \%$ \\
\hline Ratings of most helpful positive reviews & 0.03 & 0.048 & 0.064 & 0.039 & 0.037 & 0.036 & 0.01 & 0.046 & 0.014 & 0.023 & $3 \%$ \\
\hline Sentiment Polarity & 0.012 & 0.022 & 0.025 & 0.027 & 0.018 & 0.023 & 0.019 & 0.038 & 0.054 & 0.026 & $3 \%$ \\
\hline
\end{tabular}



Figure 1 Neural Network example

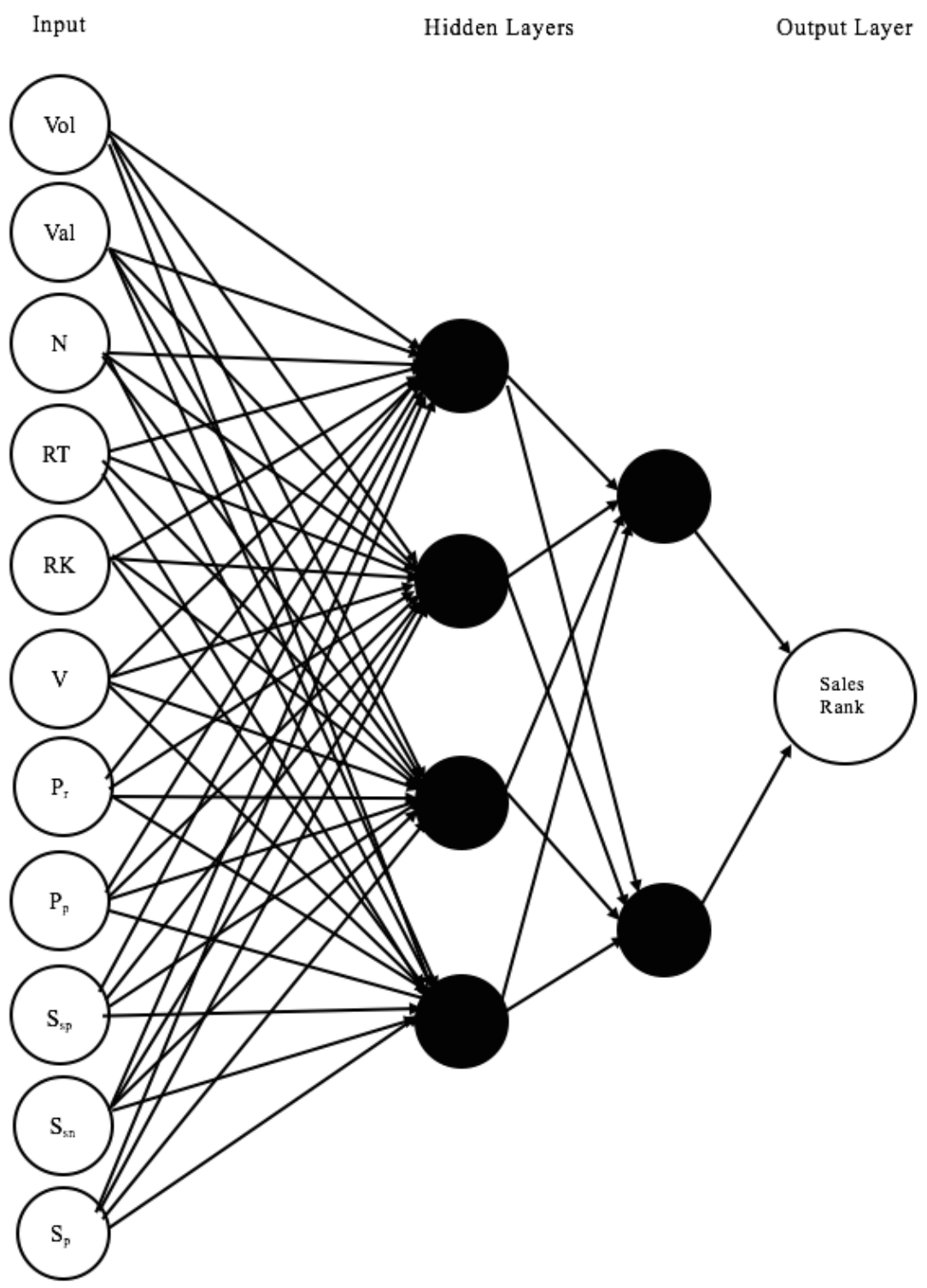

Notes:

Vol $=$ Review Volume

Val $=$ Review Valence

$\mathrm{N}=$ No. of People who find reviews helpful

$\mathrm{RT}=$ Ratings of most helpful positive review

$\mathrm{RK}=$ Reviewer Ranking

$\mathrm{V}=$ Helpful votes of reviewers

$\operatorname{Pr}=$ Picture of reviewer

$\mathrm{Pp}=$ Picture of Products 
Ssp $=$ Sentiment Strength (Positive)

$\mathrm{Ssn}=$ Sentiment Strength (Negative)

$\mathrm{Sp}=$ Sentiment Polarity 